\title{
Incidence and Clinicopathological Features of Breast Cancer in the Northern Emirates: Experience from Sharjah Breast Care Center
}

This article was published in the following Dove Press journal: International Journal of Women's Health

\author{
Riyad Bendardaf $\mathbb{I}^{1,2}$ \\ Fatemeh \\ Saheb Sharif-Askari iD ${ }^{3}$ \\ Narjes \\ Saheb Sharif-Askari (iD ${ }^{3}$ \\ Salman Yousuf Guraya (iD) ${ }^{2}$ \\ Sawsan A AIMadhi ${ }^{4}$ \\ Salah Abusnana (iD) 2,5 \\ 'Oncology Unit, University Hospital \\ Sharjah, Sharjah, United Arab Emirates; \\ ${ }^{2}$ Clinical Sciences Department, College of \\ Medicine, University of Sharjah, Sharjah, \\ United Arab Emirates; ${ }^{3}$ Sharjah Institute \\ of Medical Research, College of Medicine, \\ University of Sharjah, Sharjah, United \\ Arab Emirates; ${ }^{4}$ The Pink Caravan, \\ Friends of Cancer Patients Society, \\ Sharjah, United Arab Emirates; \\ ${ }^{5}$ Department of Diabetes and \\ Endocrinology, University Hospital \\ Sharjah, Sharjah, United Arab Emirates
}

Correspondence: Fatemeh Saheb

Sharif-Askari

Sharjah Institute of Medical Research,

College of Medicine, University of

Sharjah, Sharjah, United Arab Emirates

Tel +971501829166

Email fsharifaskari@sharjah.ac.ae
Background: Breast cancer is the most frequently reported cancer among women in the Middle East and North Africa (MENA) region. However, the available data about women breast cancer from the MENA and particularly from the Northern Emirates region of the United Arab Emirates (UAE) are scarce and inconsistent. Therefore, this study estimated the incidence, patient-specific factors including $25(\mathrm{OH}) \mathrm{D}$ levels, and clinicopathological features of breast cancer in women from the Northern Emirates.

Methods: We conducted this retrospective case-control study on 1,048 women who were referred to the Sharjah Breast Care Centre at University Hospital Sharjah between March 2016 and July 2018. Multivariate logistic regression was used for the statistical analysis of clinical data.

Results: Out of 1048 women with breast-related conditions referred to our canter, 94 (10\%) were diagnosed with breast cancer ( 1 in 11), and approximately 1 in 5 of these women was younger than 40 years. After adjusting for age, body mass index and menopause status, women with serum 25-hydroxyvitamin D [25(OH)D] levels lower than $20 \mathrm{ng} / \mathrm{mL}$ were found to be at higher risk of breast cancer (odd ratio, 4.63; 95\% CI, 2.61-8.23). The majority of breast cancer cases had invasive-ductal carcinoma with hormone-positive receptor molecular subtype ( 78 cases out of 94, 83\%). HER 2 overexpressing tumor ( $3+$ by immunohistochemistry (IHC) or by fluorescence in situ hybridization (FISH)) was seen more in women younger than 40 years as compared to older women ( 7 cases out of 19 HER2 expressed tumors, $p=0.007$ ).

Conclusion: Our study cohort showed a mean age of diagnosis of breast cancer in women a decade earlier than in the developed countries. Furthermore, women with breast cancer tend to be serum 25(OH)D deficient at diagnosis and to have luminal A tumors.

Keywords: breast cancer, luminal subtypes, HER2 expression, serum 25(OH)D deficiency, Northern Emirates

\section{Introduction}

Breast cancer is the most common cancer in women worldwide. ${ }^{1,2}$ In the UAE, breast cancer is the most frequent malignancy among women, accounting for approximately one-third $(38.8 \%)$ of all cancers in $2014 .^{3}$ There are few reports about incidence rates and clinicopathological characteristics of the breast cancer from the MENA region (MENA). ${ }^{4,5}$ These studies have reported the mean age of diagnosis of breast cancer in the MENA region to be under 50 years, with the majority of breast cancer cases being of the hormone-receptor negative type. The 
reported clinicopathological manifestations of the breast cancer in these studies are mostly related to the cases diagnosed in the North Africa such as Tunisia. Such variations in geographical representation of the women's breast cancer in the MENA makes it even harder for a standard and accurate epidemiological data. A recent report by Asiri et al from Saudi Arabia has shown that eight out of 1000 patients were diagnosed with breast cancer during 2010-2017. ${ }^{6}$ The investigators have also eluded that average age at the diagnosis of invasive breast cancer was 56 years, while ductal carcinoma was the most common variant of breast cancer. The highest incidence rates of breast cancer in women are reported in women between 45 and 49 of age. ${ }^{3}$ The UAE National Cancer Registry has reported an increasingly younger age for the onset of breast cancer in women in the country. ${ }^{3}$ Therefore, the ability to identify patientspecific factors of breast cancer that are unique to women in the UAE allows for improvements in implementation of preventive strategies as well as improved clinical decision making.

Currently, the most frequently used method for predicting risk of breast cancer is the Gail model, ${ }^{7}$ which takes into account a woman's age, age at menarche, age at first child birth, number of previous benign breast biopsies, and number of first-degree relatives with breast cancer. Although other patient-specific factors such as obesity, ${ }^{8}$ breast density, ${ }^{9}$ or vitamin $\mathrm{D}$ deficiency ${ }^{10,11}$ are also strongly associated with the risk of breast cancer, they are not included in the Gail model. Unlike most other unmodifiable risk factors in the Gail model, obesity and vitamin D deficiency are preventable. This underscore the importance of targeting patient-specific factors during breast cancer preventive interventions.

As it stands, there is no study about incidence rates and clinicopathological characteristics of the breast cancer from the Northern Emirates. Moreover, the patientspecific factors that can potentially help in identifying women at risk of developing breast cancer in this region are not clearly understood. As a result, currently, clinicians tend to make random ad hoc decisions about the suitable patients who would receive routine breast cancer screening. This practice would certainly delay the establishment of diagnosis and management plans in high-risk patients. Therefore, this study aimed to estimate the incidence, patients-specific factors, and clinicopathological features of the breast cancer in women from the Northern Emirates.

\section{Materials and Methods}

\section{Study Design and Participants}

We conducted this retrospective case-control study at the Sharjah Breast Centre of University Hospital Sharjah (UHS) in Sharjah UAE. This center offers advanced breast cancer care including screening, diagnosis and treatment of breast cancer in the UAE. We reviewed medical records of all consecutive patients with breast complaints who were managed in the center between March 2016 and July 2018. All patients younger than 15 years were excluded from this study. A sample size of 810 was assessed to provide $>90 \%$ power to detect a significant difference $(\alpha=0.05) .{ }^{12}$ Ethical approval was obtained from the University Hospital Sharjah Ethics Committee (UHS-HERC-01-28012019). All methods were performed in accordance with the relevant guidelines (Declaration of Helsinki and the Belmont Report). Written informed consent was obtained from all study participants.

\section{Data Collection}

We collected the data about demographic characteristics such as age, and body mass index (BMI); comorbid conditions including diabetes mellitus, hypertension, hypothyroidism, poly-cystic ovary syndrome, and iron-deficiency anemia. The laboratory data such as serum $25(\mathrm{OH}) \mathrm{D}$ level and radiology findings of BI-RADS breast density and mammogram BI-RADS were also recorded for each patient. We divided patients into malignant or non-malignant (benign) cases. For the malignant cases, clinicopathological characteristics including tumor location, type of breast cancer, molecular subtype of breast cancer, receptors, tumor location, tumor size were recorded. The TNM classification was registered according to the 8th edition of the AJCC (American Joint Committee on Cancer); ${ }^{13}$ whereas the histological classification was registered according to the WHO classification.

\section{Serum 25(OH)D Measurement}

Serum 25(OH)D level was measured using chemiluminescent immunoassay (DiaSorin, LIAISON $25{ }^{\circledR}$ Vitamin D TOTAL Assay), according to the manufacturer's instructions. The coefficient of variation for the instrument was between $10 \%$ and $15 \%$, and the sensitivity for the assay was $4 \mathrm{ng} / \mathrm{mL}^{.14,15}$

\section{Statistical Analysis}

Incidence of Breast Cancer

For the cumulative study population data, the crude agespecific incidence was calculated using the number of incident breast cancer cases as the numerator and the 
total person-years in the at-risk population during the same period as the denominator. Age standardization of incidence rates was then carried out by direct method using the world standard population. ${ }^{16}$

\section{Univariate Analysis of Variables}

Continuous normally distributed variables were presented as mean standard deviation (SD), or as median interquartile range (IQR) in case of skewed distribution. The categorical variables were reported as counts and percentages. In the univariate analysis, variables were compared across groups using the chi-square $\left(X^{2}\right)$ test for categorical data and Student's $t$-test or Wilcoxon test for continuous data, if their distribution was skewed.

\section{Multivariate Analysis for the Association of Serum 25(OH) Deficiency with the Breast Cancer}

The association between serum 25(OH)D level lower than $20 \mathrm{ng} / \mathrm{mL}$ and the risk of breast cancer was identified using a logistic regression model, which was adjusted for age, BMI, and menopausal status. These cofounding variables were selected for logistic regression model according to their clinical and statistical significance. ${ }^{17,18}$ All analyses were two-sided, with a $p$-value of $<0.05$ being statistically significant. The quantitative analysis was done through the statistical software packages of SPSS 25.00 (SPSS Inc., Chicago, IL, USA).

\section{Model Performance Evaluation}

At this stage, the performance of the developed model was evaluated using tests of calibration and discrimination. Calibration was measured using the Hosmer and Lemeshow goodness of fit test, ${ }^{19,20}$ while the discriminatory power was assessed by concordance statistics (C statistics). ${ }^{21,22}$ The accuracy of model was evaluated using positive predictive value and negative predictive value. Finally, the sensitivity and specificity of each variable were also calculated.

\section{Internal Validity}

We assessed the internal validity of our logistic regression model using the bootstrapping method. ${ }^{23,24}$ A total of 1000 bootstrap replicates were used to evaluate the stability of our regression coefficients.

\section{Results}

A total of 1,075 cases were referred to the Sharjah Breast Care Centre during the study period. We excluded 27 patients as they were younger than 15 years. Finally, 1,048 patients were included in our analysis; 94 (9\%) had breast cancer, while 954 (91\%) were diagnosed with benign breast lesions.

\section{Incidence of Breast Cancer}

The age distribution and the age-specific incidence rates are presented in Table 1 . In our cohort, we found the total world-age standardized incidence ratio (W-ASIR) of 4.51 for the risk of breast cancer for all ages. This incidence rate increased with advancing age and reached the maximum in women older than 60 years (W-ASIR $=2.37)$.

\section{Clinical Characteristics of Malignant and Benign Breast Diseases}

The clinical characteristics of malignant and benign cases are shown in Table 2. The mean age of the study cohort was $46 \pm 11$ years, range 15-95 years. On average, malignant cases were five years older than benign cases (51 years in malignant versus 46 years in benign cases, $p<0.001)$. Of note, over half of all malignant cases were aged $\leq 50$ years at the time of diagnosis ( 49 cases out of 94 , $52 \%$ ), and one-third of them were younger than 40 years (16 cases out of 48). At presentation, compared to benign cases, nearly half of malignant cases were obese with a BMI of 30 and above (43\% in malignant versus $15 \%$ in benign cases, $p<0.001)$, and postmenopausal ( $48 \%$ in malignant versus $33 \%$ in benign cases, $p<0.001$ ). In addition, malignant cases had a lower baseline mean serum $25(\mathrm{OH}) \mathrm{D}$ levels as compared to benign cases (mean [standard deviation] $16.41^{10}$ in malignant versus $21.16^{10} \mathrm{ng} / \mathrm{mL}$ in benign cases, $p=0.015$ ) [Figure 1].

Table I Crude and Age-Standardized Incidence Rate

\begin{tabular}{|l|l|l|l|}
\hline $\begin{array}{l}\text { Age } \\
\text { Group } \\
\text { (Years) }\end{array}$ & $\begin{array}{l}\text { Breast } \\
\text { Cancer }\end{array}$ & $\begin{array}{l}\text { Age-Specific } \\
\text { Incidence (per } \\
10^{5} \text { Years) }\end{array}$ & $\begin{array}{l}\text { World Age- } \\
\text { Standardized } \\
\text { Incidence Rate } \\
\text { X 100,000 (W-ASIR) }\end{array}$ \\
\hline $10-19$ & 0 & 0 & 0 \\
$20-29$ & 0 & 0 & 0 \\
$30-39$ & 16 & 2.08 & 0.14 \\
$40-49$ & 33 & 13.69 & 0.82 \\
$50-59$ & 24 & 25.89 & 1.16 \\
$\geq 60$ & 21 & 67.98 & 2.37 \\
\hline Total & 94 & & 4.51 \\
\hline
\end{tabular}


Table 2 Comparison of Clinical Characteristics of Malignant and Benign Cases

\begin{tabular}{|c|c|c|c|c|}
\hline & $\begin{array}{l}\text { Total } \\
(n=1048)\end{array}$ & $\begin{array}{l}\text { Malignant } \\
(n=94)\end{array}$ & $\begin{array}{l}\text { Benign } \\
(n=954)\end{array}$ & $P$-value \\
\hline \multicolumn{5}{|l|}{ Demographic data } \\
\hline Age at diagnosis, mean (SD), years & $46(11)$ & $51(12)$ & 46 (II) & $<0.001$ \\
\hline \multicolumn{5}{|l|}{ Age n (\%) years } \\
\hline$<40$ & $267(25)$ & $16(17)$ & $25 \mathrm{I}(26)$ & \\
\hline $40-49$ & 405 (39) & $33(35)$ & $373(39)$ & \\
\hline $50-59$ & $25 \mid(24)$ & $24(25)$ & $225(24)$ & \\
\hline$\geq 60$ & $125(12)$ & $21(22)$ & $105(11)$ & $<0.001$ \\
\hline \multicolumn{5}{|l|}{ Physical examination } \\
\hline Height, mean (SD) & $159.46(6)$ & $159.77(6)$ & $157.85(6)$ & 0.011 \\
\hline Weight [kg], mean (SD) & $74.37(16)$ & $76.73(14)$ & $73.93(16)$ & 0.127 \\
\hline \multicolumn{5}{|l|}{ BMI, n (\%) } \\
\hline Normal (I8.5-24.9) & $694(66)$ & $27(29)$ & $664(70)$ & $<0.001$ \\
\hline Overweight $(25-30)$ & $173(16)$ & $27(29)$ & $146(15)$ & \\
\hline Obese $>30$ & $185(18)$ & $40(43)$ & $144(15)$ & \\
\hline Menopause, $\mathrm{n}(\%)$ & $350(34)$ & $45(48)$ & $305(33)$ & 0.004 \\
\hline \multicolumn{5}{|l|}{ Laboratory data } \\
\hline Serum $25(\mathrm{OH}) \mathrm{D}$, mean $(\mathrm{SD}), \mathrm{ng} / \mathrm{mL}$ & $19.57(10)$ & $16.41(10)$ & $21.16(10)$ & 0.015 \\
\hline
\end{tabular}

\section{Serum 25(OH)D Levels in the Study} Cohort as a Risk for Breast Cancer

In the multivariate analysis of malignant and benign cases, after adjusting for age, BMI, and menopausal status, the serum 25-hydroxyvitamin D [25(OH)D] levels lower than $20 \mathrm{ng} / \mathrm{mL}$ remained independently associated with malignancy.

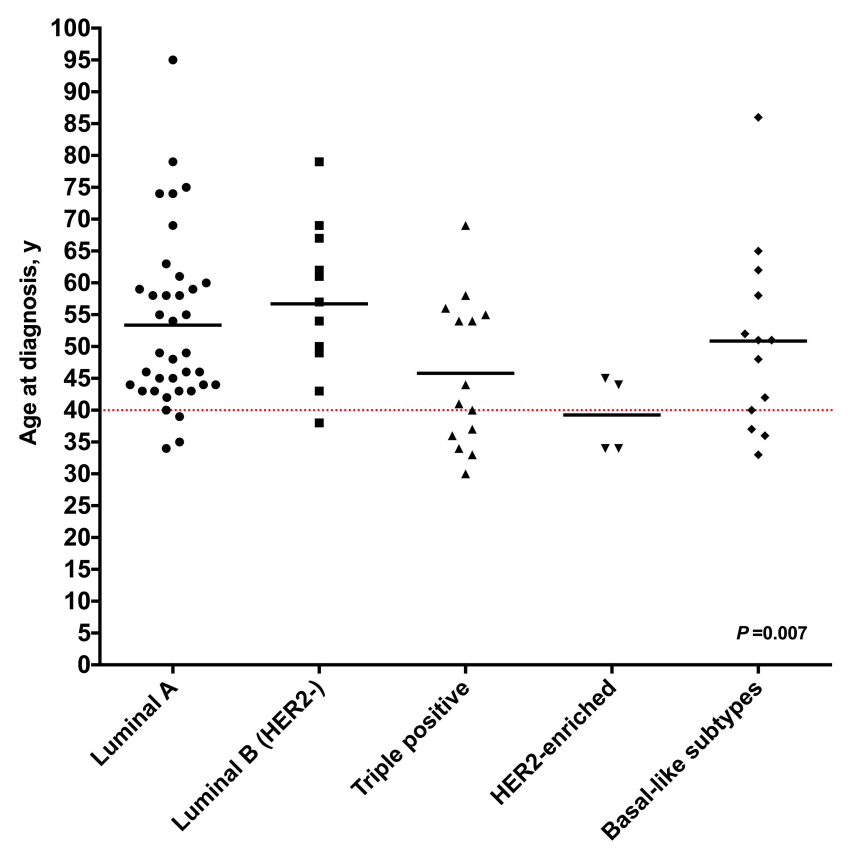

Figure I Serum 25(OH)D level between benign and malignant cases.
Likewise, the bootstrap procedure did not influence the results of the initial regression analysis. Table 3 shows crude, adjusted, and bootstrapped $\mathrm{Cl}$ of multivariate analysis. The C-statistic for multivariate regression model was 0.72 (95\% CI $0.66-0.78)$. The multivariate model demonstrated a good calibration; the Hosmer-Lemeshow statistic value of 0.80 , and a strong predictive ability for serum $25(\mathrm{OH}) \mathrm{D}$ deficient malignant status ( $\mathrm{n}=1048$, sensitivity $(\%)$ of 68 , specificity $(\%)$ of 61 , positive predictive value (\%) of 98 , and negative predictive value $(\%)$ of 10$)$.

\section{Clinicopathological Profile of the Patients with Breast Cancer}

The clinicopathological profile of 94 malignant cases is shown in Table 4. A great majority of women with breast cancer had invasive-ductal carcinoma $(n=79,84 \%)$, with hormone-receptors positive subtypes (estrogen-receptor and/or progesterone-receptor positive) $(n=62,66 \%)$ as shown in Table 4. Furthermore, HER2 overexpressing tumor $(3+$ by immunohistochemistry (IHC) or by fluorescence in situ hybridization (FISH)) was seen more in women younger than 40 years as compared to older women (7 cases out of 19 HER2 expressed tumors, $p=0.007$ ) [Figure 2].

\section{Discussion}

This study provides insight into the nature and type of breast cancer in the UAE. The most striking feature 
Table 3 Association Between Serum 25(OH)D Levels and Breast Cancer Risk

\begin{tabular}{|l|l|l|l|l|}
\hline Variables & $\begin{array}{l}\text { Crude OR } \\
(\mathbf{9 5 \%} \mathbf{~ C l})\end{array}$ & $\begin{array}{l}* * \text { Adjusted OR } \\
(\mathbf{9 5 \%} \mathbf{C l})\end{array}$ & P-value & Bootstrap (95\% BootCl) \\
\hline Vitamin D deficiency* & $10.19(5.94-17.49)$ & $4.63(2.61-8.23)$ & $<0.001$ & $(2.20-7.67)$ \\
\hline
\end{tabular}

Notes: *Vitamin $D$ deficiency is defined as serum $25(\mathrm{OH}) \mathrm{D}$ levels lower than $20 \mathrm{ng} / \mathrm{mL}$; **Adjusted for age, menopausal status and BMI.

Abbreviation: $O R$, odd ratio.

of this study was the finding of 1 breast cancer in every 11 women with breast-related conditions, and the fact that 1 in 5 of breast cancer cases was younger than 40 years. The majority of cases were invasiveductal carcinoma with hormone-positive receptor molecular subtype (Luminal A). Tumors with HER2 overexpression were seen more in younger cases. Furthermore, women with breast cancer were found to have lower serum 25(OH)D levels as compared with benign cases.

Table 4 Clinicopathological Characteristics of Malignant Cases

\begin{tabular}{|l|l|}
\hline & $\begin{array}{l}\text { Malignant } \\
\text { (n=94) }\end{array}$ \\
\hline $\begin{array}{l}\text { Type of breast cancer, } \mathbf{n} \text { (\%) } \\
\text { IDC }\end{array}$ & $79(84)$ \\
ILC & $5(5)$ \\
Mixed IDC and ILC & $5(5)$ \\
Mucinous carcinoma & $3(3)$ \\
Ductal carcinoma in situ & $1(1)$ \\
Mammary carcinoma & $1(1)$ \\
\hline Molecular subtype of breast cancer, $\mathbf{n}$ (\%) & \\
Luminal A* & $34(36)$ \\
Luminal B (HER2-)** & $13(14)$ \\
Triple positive & $15(16)$ \\
HER2-enriched & $4(4)$ \\
Basal-like subtypes & $12(13)$ \\
\hline Receptor status, $\mathbf{n}$ (\%) & \\
ER & $6 I(65)$ \\
PR & $57(6 I)$ \\
HER2*** & $19(20)$ \\
Ki67**** & $29(3 \mathrm{I})$ \\
E-cadherin & $1 \mathrm{I}(12)$ \\
\hline Tumor location, $\mathbf{n}$ (\%) & \\
Left & $57(6 I)$ \\
Right & $34(36)$ \\
Bilateral & $3(3)$ \\
\hline Tumor size, mean (SD), cm & $2.40(2)$ \\
\hline
\end{tabular}

Notes: *Ki67 was defined as Immunoreactive in > or $=14 \%$ in malignant cells; ** Luminal A was defined as ER and/or PR positive, ki67 low (<14\%); ****Luminal B was defined as ER and/or PR positive, ki67 high (>14\%); ****HER2 expressing tumor (3+ by immunohistochemistry (IHC) or by fluorescence in situ hybridization (FISH)).
The reported incidence rate of 4.5 per 100,000 women in our study is comparable with the incidence reported by Saudi Arabia (4.8 per 100,000 women), ${ }^{25,26}$ however, it is much lower than the reported incidence from the developed countries (16 per 100,000 women). ${ }^{2}$ Additionally, the mean age at breast cancer diagnosis in our study was consistent with other neighboring countries such as Oman and Saudi Arabia, ${ }^{26}$ at 49 years compared with that of developed countries ${ }^{2}$ where the reported median age at diagnosis is 60 years. This difference could be due

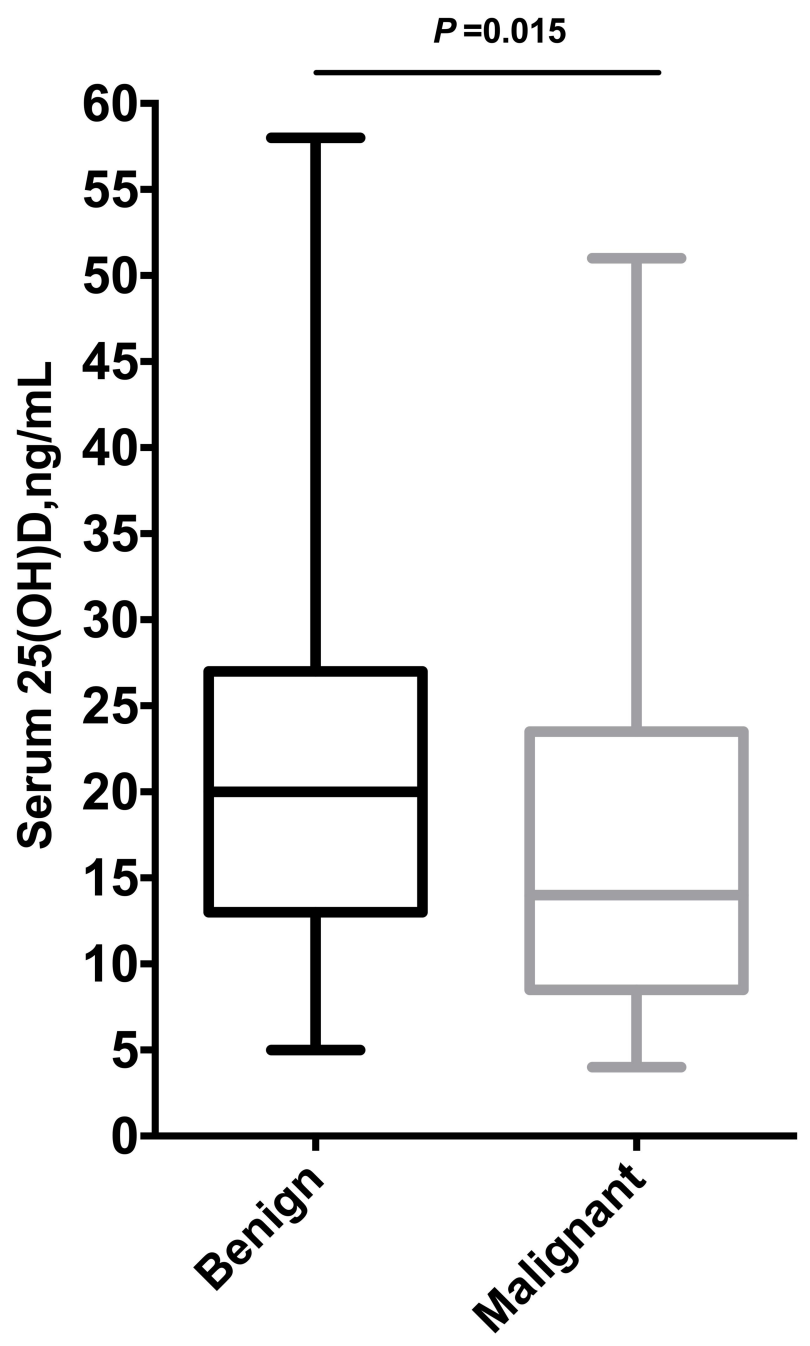

Figure 2 Age difference among different breast cancer molecular subtypes. 
to younger median age in the MENA region compared to the United States and Europe. ${ }^{4}$ Furthermore, the majority of cases reported in our study were identified through the Pink Caravan Program that helped in the early diagnosis of the breast cancer. The Pink Caravan Program offers free mammograms screening for all high-risk women for breast cancer across the UAE. Finally, this lower mean age could also be partly due to the possibility that elder women are less likely to undertake mammograms than their younger counterparts and, therefore, are underrepresented in breast cancer studies. ${ }^{4}$ The major challenge is that breast cancer in younger age tends to be more aggressive and associated with poorer prognosis and shorter survival rates. ${ }^{27}$ Therefore, a precise and structured risk-stratified breast cancer screening and management program tailored for all women from middle age onwards is needed.

A majority of women with breast cancer in our study were serum $25(\mathrm{OH}) \mathrm{D}$ deficient at the time of diagnosis. This finding is in line with several epidemiological studies that have found inverse association between lower levels of serum $25(\mathrm{OH}) \mathrm{D}$ at the time of diagnosis and high breast cancer risk. ${ }^{10,11}$ However, current study is among the first, to our knowledge that has evaluated the relationship between serum $25(\mathrm{OH}) \mathrm{D}$ and breast cancer in women living in the UAE. This area is rich in high UV sunlight but the potentially low serum $25(\mathrm{OH}) \mathrm{D}$ status reported in our study is linked to cultural type of clothing. Vitamin D has been reported to be anti-proliferative marker in the human body, ${ }^{28}$ and vitamin $\mathrm{D}$ receptors have been found to be inversely associated with Ki-67 expression in breast cancer biopsies of women older than 50 years. $^{29}$ Therefore, our study stresses the need to optimizing vitamin D deficiently in an attempt to reduce the risk of breast cancer among women in the UAE.

Our study has shown that hormone receptor-positive tumors were predominant in women of all ages and HER2 overexpression tumors were seen more in younger ages. In sharp contrast, hormone receptor-negative and HER2 overexpression are reported from the tumors in the MENA region. ${ }^{4}$

The current study is novel in focusing on women in the UAE; a group at greater risk of vitamin D deficiency and who have serum 25(OH)D levels lower than $20 \mathrm{ng} / \mathrm{mL}$. The opportunity to determine the incidence of breast cancer is an additional strength of our study design.

In conclusion, our study has shown that mean age at the time of diagnosis of breast cancer in women from the Northern Emirates is a decade earlier than in the developed countries. Furthermore, women with breast cancer tend to be serum $25(\mathrm{OH}) \mathrm{D}$ deficient at the time of diagnosis and to have luminal A tumors. Tumors with HER2 overexpression were seen more frequently in women younger than 40 years compared to older women.

\section{Study Limitations}

An intrinsic limitation of this study is the absence of a model for randomized controlled trial. By using a multivariate logistic regression model, we were able to adjust the observed confounders such as BMI and menopausal status and to assess the association of serum level of $25(\mathrm{OH}) \mathrm{D}$ and breast cancer risk. However, there might be a number of unobserved factors that could only be controlled with a randomized controlled trial. Additionally, because of the single-institutional nature of the study, we were able to collect a small sample of patients. A well designed clinical validation is necessary by conducting clinical trials on larger cohorts.

\section{Disclosure}

The authors declare that there is no conflict of interest.

\section{References}

1. Jemal A, Center MM, DeSantis C, et al. Global patterns of cancer incidence and mortality rates and trends. Cancer Epidemiol Prev Biomarkers. 2010;19:1893-1907. doi:10.1158/1055-9965.EPI-100437

2. Bray F, Ferlay J, Soerjomataram I, et al. Global cancer statistics 2018: GLOBOCAN estimates of incidence and mortality worldwide for 36 cancers in 185 countries. CA Cancer J Clin. 2018;68:394-424.

3. Cancer Incidence in United Arab Emirates. Annual report of the UAE. National Cancer Registry; 2014.

4. Chouchane L, Boussen H, Sastry KSR. Breast cancer in Arab populations: molecular characteristics and disease management implications. Lancet Oncol. 2013;14(10):e417-e424. doi:10.1016/ S1470-2045(13)70165-7

5. Khairy GA, Guraya SY, Ahmed ME, et al. Bilateral breast cancer. Incidence, diagnosis and histological patterns. Saudi Med J. 2005;26 (4):612.

6. Asiri S, Asiri A, Ulahannan S, et al. Incidence rates of breast cancer by age and tumor characteristics among Saudi women: recent trends. Cureus. 2020;12(1).

7. Gail MH, Brinton LA, Byar DP, et al. Projecting individualized probabilities of developing breast cancer for white females who are being examined annually. J Natl Cancer Inst. 1989;81 (24):1879-1886. doi:10.1093/jnci/81.24.1879

8. Eliassen AH, Colditz GA, Rosner B, et al. Adult weight change and risk of postmenopausal breast cancer. JAMA. 2006;296(2):193-201. doi:10.1001/jama.296.2.193

9. McCormack VA, Dos Santos Silva I. Breast density and parenchymal patterns as markers of breast cancer risk: a meta-analysis. Cancer Epidemiol Prev Biomarkers. 2006;15(6):1159-1169. doi:10.1158/ 1055-9965.EPI-06-0034

10. Garland CF, Gorham ED, Mohr SB, et al. Vitamin D and prevention of breast cancer: pooled analysis. J Steroid Biochem Mol Biol. 2007;103(3-5):708-711. 
11. Yao S, Kwan ML, Ergas IJ, et al. Association of serum level of vitamin $\mathrm{D}$ at diagnosis with breast cancer survival: a case-cohort analysis in the pathways study. JAMA oncol. 2017;3(3):351-357. doi:10.1001/jamaoncol.2016.4188

12. Faul F, Erdfelder E, Buchner A, et al. Statistical power analyses using $\mathrm{G}^{*}$ Power 3.1: tests for correlation and regression analyses. Behav Res Methods. 2009;41(4):1149-1160. doi:10.3758/BRM.41.4.1149

13. Amin MB, Greene FL, Edge SB, et al. The eighth edition AJCC cancer staging manual: continuing to build a bridge from a population-based to a more "personalized" approach to cancer staging. CA Cancer J Clin. 2017;67(2):93-99.

14. Ersfeld DL, Rao DS, Body JJ, et al. Analytical and clinical validation of the $25 \mathrm{OH}$ vitamin D assay for the LIAISON ${ }^{\circledR}$ automated analyzer. Clin Biochem. 2004;37(10):867-874. doi:10.1016/j.clinbiochem.2004.06.006

15. Sharif-Askari FS, Sharif-Askari NS, Halwani R, et al. Low vitamin $\mathrm{D}$ serum level is associated with HDL-C dyslipidemia and increased serum thrombomodulin levels of insulin-resistant individuals. Diabetes Metab Syndr Obes. 2020;13:1599. doi:10.2147/DMSO. S245742

16. Slwdm P. Cancer Incidence in Five Continents. Vol. VIII. IARC Scientific Publications; 2002.

17. Steyerberg EW, Eijkemans MJ, Harrell FE, et al. Prognostic modelling with logistic regression analysis: a comparison of selection and estimation methods in small data sets. Stat Med. 2000;19(8):1059-1079. doi:10.1002/(SICI)1097-0258(20000430)19:8<1059::AID-SIM412>3. $0 . \mathrm{CO} ; 2-0$

18. Peduzzi P, Concato J, Kemper E, et al. A simulation study of the number of events per variable in logistic regression analysis. J Clin Epidemiol. 1996;49(12):1373-1379. doi:10.1016/S0895-4356(96) 00236-3

19. Lemeshow S, Hosmer DW. A review of goodness of fit statistics for use in the development of logistic regression models. Am J Epidemiol. 1982;115(1):92-106. doi:10.1093/oxfordjournals.aje.a113284
20. Steyerberg EW, Vickers AJ, Cook NR, et al. Assessing the performance of prediction models: a framework for some traditional and novel measures. Epidemiology. 2010;21(1):128. doi:10.1097/EDE.0b013e3181c30fb2

21. Pencina MJ, D'Agostino RB, D'Agostino RB, et al. Evaluating the added predictive ability of a new marker: from area under the ROC curve to reclassification and beyond. Stat Med. 2008;27(2):157-172. doi:10.1002/sim.2929

22. Steyerberg EW. Clinical Prediction Models: A Practical Approach to Development, Validation, and Updating. Springer Science \& Business Media; 2008.

23. Efron B, Tibshirani RJ. An Introduction to the Bootstrap. CRC press; 1994.

24. Steyerberg EW, Harrell FE, Borsboom GJ, et al. Internal validation of predictive models: efficiency of some procedures for logistic regression analysis. J Clin Epidemiol. 2001;54(8):774-781. doi:10.1016/ S0895-4356(01)00341-9

25. Alghamdi IG, Hussain II, Alghamdi MS, et al. The incidence rate of female breast cancer in Saudi Arabia: an observational descriptive epidemiological analysis of data from Saudi cancer registry 2001-2008. Breast Cancer. 2013;5:103.

26. Mehdi I, Monem EA, Al Bahrani BJ, et al. Age at diagnosis of female breast cancer in Oman: issues and implications. South Asian $J$ Cancer. 2014;3(2):101. doi:10.4103/2278-330X.130442

27. Narod SA. Breast cancer in young women. Nat Rev Clin Oncol. 2012;9(8):460. doi:10.1038/nrclinonc.2012.102

28. Spath L, Ulivieri A, Lavra L, et al. Antiproliferative effects of $1 \alpha-\mathrm{OH}$ -vitD 3 in malignant melanoma: potential therapeutic implications. Sci Rep. 2017;7:40370. doi:10.1038/srep40370

29. Al-Azhri J, Zhang Y, Bshara W, et al. Tumor expression of vitamin D receptor and breast cancer histopathological characteristics and prognosis. Clin Cancer Res. 2017;23(1):97-103. doi:10.1158/10780432.CCR-16-0075

\section{Publish your work in this journal}

The International Journal of Women's Health is an international, peerreviewed open-access journal publishing original research, reports, editorials, reviews and commentaries on all aspects of women's healthcare including gynecology, obstetrics, and breast cancer. The manuscript management system is completely online and includes a very quick and fair peer-review system, which is all easy to use. Visit http://www.dovepress.com/testimonials.php to read real quotes from published authors. 